\title{
Recognition of Nosocomial Pneumonia in the Intensive Care Unit: Still a Confusing Issue
}

Pneumonia associated with mechanical ventilation in the intensive care unit (ICU) setting is one of the most common infections managed by intensivists. The current classification of nosocomial pneumonia includes hospitalacquired pneumonia, ventilator-associated pneumonia (VAP), and nursing home-associated pneumonia. Healthcare-associated pneumonia is the newest category of nosocomial pneumonia, and in many developed countries is probably the most common type of pneumonia requiring ICU care. Healthcare-associated pneumonia is a distinct type of nosocomial pneumonia- the others being hospitalacquired pneumonia and VAP - that is present at the time of hospital or ICU admission, where patients have specific underlying risk factors, including residence in a nursinghome or long-term care facility; recent hospitalization or treatment with antibiotics; having received home or hospital-based intravenous therapy, wound care, or dialysis; and immunosuppression. ${ }^{1-3}$ In this issue of RESPIRATORY CARE, Shan et al report a meta-analysis in which they found the diagnostic performance of the clinical pulmonary infection score (CPIS) for VAP to be moderate, compared to a reference standard of lower respiratory tract quantitative cultures. However, they also concluded that the CPIS is simple and easy to perform, which makes it potentially useful in the diagnosis and clinical management of VAP. ${ }^{4}$

See the Original Study on Page 1087

Clinical criteria are non-specific for the diagnosis of nosocomial pneumonia, including VAP. Clinical findings such as fever, leukocytosis, and purulent secretions are known to complicate other non-infectious pulmonary conditions such as atelectasis and acute respiratory distress syndrome, and therefore lack specificity for the diagnosis of nosocomial pneumonia. ${ }^{5-8}$ Similarly, chest radiograph can be non-specific for the diagnosis of nosocomial pneumonia. Wunderink et al found that no roentgenographic sign correlated well with the presence of pneumonia in mechanically ventilated patients. ${ }^{9}$ The presence of air bronchograms was the only roentgenographic sign that correlated with autopsy-verified pneumonia, correctly predicting $64 \%$ of cases. The most frequently employed clinical diagnosis of VAP has traditionally required the presence of a new or progressive consolidation on chest radiology plus at least 2 of the following clinical criteria: fever greater than $38^{\circ} \mathrm{C}$, leukocytosis or leukopenia, and purulent secretions. This definition has been supported by several medical specialty groups, ${ }^{3,10}$ despite the lack of specificity of these criteria. $^{6-9}$

More recently, attempts were made to develop prediction models and scoring systems for nosocomial pneumonia. The Centers for Disease Control and Prevention's National Healthcare Safety Network established a clinical definition for probable nosocomial pneumonia. ${ }^{11}$ Unfortunately, these diagnostic criteria have not been validated, and at least one study found that decision making using these criteria was less accurate, potentially resulting in the withholding of antibiotics in 16\% of patients diagnosed with VAP via bronchoalveolar lavage (BAL). ${ }^{12}$ Recently, we compared the observed rates of VAP with the National Healthcare Safety Network surveillance method versus the American College of Chest Physicians clinical criteria. ${ }^{13}$ Over one year, 2,060 patients required mechanical ventilation for greater than 24 hours and were prospectively evaluated. Of these, 83 patients (4\%) had VAP according to the American College of Chest Physicians criteria, as compared to 12 patients $(<1 \%)$ according to the National Healthcare Safety Network surveillance method. The corresponding VAP rates were 8.5 versus 1.2 cases per 1,000 ventilator days, respectively. The agreement of the 2 sets of criteria was poor (kappa statistic 0.26). Cultures were positive in $88 \%$ of patients in the American College of Chest Physicians group, as compared to $92 \%$ in the National Healthcare Safety Network group. ${ }^{13}$

The CPIS is another diagnostic tool for nosocomial pneumonia. The CPIS is based on 6 variables: fever; leukocytosis; tracheal secretions; oxygenation; radiographic infiltrates; and semi-quantitative cultures of samples collected via suctioning, with Gram stain. ${ }^{14}$ The original description showed a sensitivity of $93 \%$ and a specificity of $100 \%$, but that study included only 28 patients, and the CPIS was compared to quantitative culture of BAL fluid, using a "bacterial index" defined as the sum of the logarithm of all bacterial species recovered, which is not considered an acceptable standard for the diagnosis of VAP.${ }^{14}$ Compared to pathology diagnosis, CPIS has demonstrated a moderate performance, with a sensitivity of $72-77 \%$ and a specific- 


\section{Recognition of Nosocomial Pneumonia in the Intensive Care Unit}

ity of $42-85 \% .6,15$ Similarly, CPIS has been found to be only moderately accurate compared to quantitative bacterial cultures of the lower respiratory tract for the diagnosis of VAP, with a sensitivity of $30-89 \%$ and a specificity of $17-80 \% .^{16-20}$

Several studies have evaluated the value of quantitative bacteriological data in establishing the diagnosis of VAP, compared to pathology and clinical criteria. Torres et al used quantitative cultures of respiratory specimens obtained via BAL, protected BAL, protected specimen brush, and samples collected via tracheobronchial suctioning, that were compared to histology of lung biopsy samples to establish the diagnosis of VAP. ${ }^{21}$ The sensitivity for the diagnosis of VAP ranged from $16 \%$ to $37 \%$ when only histologic reference tests were used, whereas the specificity ranged from $50 \%$ to $77 \%$. When lung histology of guided or blind specimens and microbiology of lung tissue were combined, all quantitative diagnostic techniques achieved higher, but still limited, diagnostic yields (sensitivity range $43-83 \%$, specificity range $67-91 \%$ ). ${ }^{21}$ Other investigators found similar diagnostic accuracy employing histologic criteria as the reference standard. ${ }^{22-28}$ Fàbregas et al also found that addition of the results of quantitative cultures to clinical criteria (CPIS) did not increase the accuracy of CPIS in diagnosing VAP. ${ }^{6}$ More recently, Riaz et al compared nonquantitative and quantitative cultures for the diagnosis of VAP, ${ }^{29}$ and found that nonquantitative culture of BAL was fairly good at ruling out VAP but was poor at establishing the presence of VAP, because of the low specificity of the test. The available evidence suggests that there is no one absolute accepted standard for the diagnosis of VAP.

Several studies have found that procalcitonin can help differentiate bacterial infection from other inflammatory conditions (eg, acute respiratory distress syndrome and autoimmune diseases) or nonbacterial infectious (ie, viral) diseases. ${ }^{30-32}$ Therefore, procalcitonin monitoring may help limit overuse of antibiotics in patients with clinically suspected pneumonia. ${ }^{32-34} \mathrm{~A}$ high procalcitonin level at admission and at day 3 appears to be a good predictor of treatment failure in patients with respiratory infection, whereas a low procalcitonin level supports a clinical response and suggests shortening or discontinuing antibiotics. ${ }^{34,35}$ The use of procalcitonin to limit unnecessary antibiotics has been most extensively evaluated in patients with community-acquired pneumonia. ${ }^{33,34}$ In a recent study, Briel et al randomized patients to either procalcitoninguided antibiotic therapy or standard approach. ${ }^{35}$ For patients randomized to procalcitonin-guided therapy, the use of antibiotics was discouraged based on levels (procalcitonin $\leq 0.1 \mu \mathrm{g} / \mathrm{L}$ or $\leq 0.25 \mu \mathrm{g} / \mathrm{L}$, respectively) or encouraged (procalcitonin $>0.25 \mu \mathrm{g} / \mathrm{L}$ ). With procalcitoninguided therapy the antibiotic prescription rate was $72 \%$ lower (95\% CI 66-78\%) than with standard therapy. These types of investigations suggest that procalcitonin-guided therapy can reduce antibiotic use for respiratory tract infections in the out-patient setting without compromising patient outcomes.

Similar preliminary results have been observed for the use of procalcitonin in nosocomial pneumonia, although the findings have been mixed. Ramirez et al found that sequential procalcitonin measurement had the best sensitivity and specificity for VAP, compared to C-reactive protein and the CPIS. ${ }^{36}$ However, Luyt et al found that procalcitonin level, and the rise in procalcitonin compared to baseline, had poor diagnostic value for VAP. ${ }^{37}$ Although procalcitonin level may not be accurate for the diagnosis of VAP, ${ }^{38}$ emerging data suggest that serial procalcitonin measurement may be used as a marker to terminate antimicrobial therapy and as a biomarker for sepsis. ${ }^{39}$ The best support for procalcitonin's ability to limit unnecessary antibiotic therapy in patients with suspected lung infections, including VAP, comes from a recent trial that found an antibiotic duration reduction of almost 3 days compared to standard treatment. ${ }^{40}$ However, in the control group the clinicians were allowed to determine when antibiotics should be discontinued, without having a rigorous protocol in place to guide antibiotic management. ${ }^{41}$

As none of the currently available diagnostic tests provides an absolutely accurate diagnosis of VAP when used alone, a strategy that combines diagnostic modalities may be advantageous. Patients with suspected VAP should undergo an evaluation that is supported by local expertise and should include imaging (chest radiograph and/or computed tomography), bacteria cultures from the lower respiratory tract, and possibly biomarkers. The results of this evaluation can be used to determine the likelihood of VAP and to guide therapy in a manner that attempts to optimize patient outcomes. Ensuring timely administration of appropriate antimicrobial therapy optimizes patient outcomes, and avoiding unnecessary antibiotic exposure minimizes the emergence of antimicrobial resistance. For unstable patients, delaying the initiation of appropriate antibiotic therapy should be avoided, because such delay is associated with higher mortality. ${ }^{42}$ Therapy should not be postponed for the results of diagnostic studies. Alternatively, in stable patients, lower respiratory tract sampling via BAL or protected specimen brush reduces antibiotic use in patients with suspected VAP. $.3-45$

A recent meta-analysis of 4 randomized studies, which included a total of 628 patients, found that invasive VAP diagnosis strategies did not alter mortality. ${ }^{46}$ This finding was confirmed in a recent large randomized trial from Canada, which compared VAP diagnosis via a clinical approach to via BAL plus quantitative cultures. ${ }^{47}$ There was no significant difference between the study arms in clinical outcomes or antibiotics use. Since invasive sampling for suspected VAP does not directly affect initial 


\section{Recognition of Nosocomial Pneumonia in the Intensive Care Unit}

antibiotic prescription, it is not surprising that it does not alter mortality. ${ }^{48}$ The results of lower respiratory tract cultures are principally used to modify the initial antimicrobial regimen: de-escalation if the patient is improving, or escalation if the initial regimen was inappropriate for the offending pathogen.

In summary, the diagnosis of nosocomial pneumonia, and in particular VAP, can be confusing and problematic. However, clinicians should develop local strategies based on available resources, that attempt to balance the need to treat potentially serious infections in an appropriate and timely manner with the need to avoid unnecessary antibiotic exposure. Relatively simple protocols or guidelines can be developed at the local hospital level to accomplish these goals. ${ }^{49,50}$

\section{Marin H Kollef MD}

Division of Pulmonary and Critical Care Medicine Washington University School of Medicine St Louis, Missouri

\section{REFERENCES}

1. Hiramatsu K, Niederman MS. Health-care-associated pneumonia: a new therapeutic paradigm. Chest 2005;128(6):3784-3787.

2. Kollef MH, Shorr A, Tabak YP, Gupta V, Liu LZ, Johannes RS. Epidemiology and outcomes of health-care-associated pneumonia: results from a large US database of culture-positive pneumonia. Chest 2005;128(6):3854-3862. Erratum in: Chest 2006;129(3):831.

3. American Thoracic Society; Infectious Diseases Society of America. Guidelines for the management of adults with hospital-acquired, ventilator-associated, and healthcare-associated pneumonia. Am J Respir Crit Care Med 2005;71(4):388-416.

4. Shan J, Chen HL, Zhu JH. Diagnostic accuracy of clinical pulmonary infection score for ventilator-associated pneumonia: a meta-analysis. Respir Care 2011;56(8):1087-1094.

5. Morrow LE. Prevention strategies for healthcare-associated pneumonia. Semin Respir Crit Care Med 2009;30(1):86-91.

6. Fàbregas N, Ewig S, Torres A, El-Ebiary M, Ramirez J, de la Bellacasa JP, et al. Clinical diagnosis of ventilator associated pneumonia revisited: comparative validation using immediate post-mortem lung biopsies. Thorax 1999;54(10):867-873.

7. Rea-Neto A, Youssef NC, Tuche F, Brunkhorst F, Ranieri VM, Reinhart K, Sakr Y. Diagnosis of ventilator-associated pneumonia: a systematic review of the literature. Critical Care 2008;12(2):R56.

8. Vincent JL, de Souza Barros D, Cianferoni S. Diagnosis, management, and prevention of ventilator-associated pneumonia. Drugs 2010; 70(15):1927-1944.

9. Wunderink RG, Woldenberg LS, Zeiss J, Day CM, Clemins J, Lacher DA. The radiologic diagnosis of autopsy-proven ventilator-associated pneumonia. Chest 1992;101(2):458-463.

10. Pingleton SK, Fagon JY, Leeper KV Jr. Patient selection for clinical investigation of ventilator-associated pneumonia. Criteria for evaluating diagnostic techniques. Chest 1992;102(5 Suppl 1):553S-556S.

11. Centers for Disease Control and Prevention. Healthcare-associated infections (HAIs). http://www.cdc.gov/hai. Accessed June 13, 2011.

12. Miller PR, Johnson JC 3rd, Karchmer T, Hoth JJ, Meredith JW, Chang MC. National nosocomial infection surveillance system: from benchmark to bedside in trauma patients. J Trauma 2006;60(1):98103.
13. Skrupky L, McConnell K, Dallas J, McMullen K, Boyle W, Kollef M. A comparison of VAP rates as identified according to National Healthcare Safety Network (NSHN) and American College of Chest Physicians (ACCP) criteria in a medical/surgical ICU population (abstract). Crit Care Med 2010;38(12 Suppl):A403.

14. Pugin J, Auckenthaler R, Mili N, Janssens JP, Lew PD, Suter PM. Diagnosis of ventilator-associated pneumonia by bacteriologic analysis of bronchoscopic and nonbronchoscopic 'blind' bronchoalveolar lavage fluid. Am Rev Respir Dis 1991;143(5 Pt 1):1121-1129.

15. Papazian L, Thomas P, Garbe L, Guignon I, Thirion X, Charrel J, et al. Bronchoscopic or blind sampling techniques for the diagnosis of ventilator-associated pneumonia. Am J Respir Crit Care Med 1995; 152(6 Pt 1):1982-1991.

16. Croce MA, Swanson JM, Magnotti LJ, Claridge JA, Weinberg JA, Wood GC, et al. The futility of the clinical pulmonary infection score in trauma patients. J Trauma 2006;60(3):523-527. discussion 527 528.

17. Luyt CE, Chastre J, Fagon JY. Value of the clinical pulmonary infection score for the identification and management of ventilatorassociated pneumonia. Intensive Care Med 2004;30(5):844-852.

18. Schurink CA, Van Nieuwenhoven CA, Jacobs JA, Rozenberg-Arska $\mathrm{M}$, Joore HC, Buskens E, et al. Clinical pulmonary infection score for ventilator-associated pneumonia: accuracy and inter-observer variability. Intensive Care Med 2004;3(2)0:217-224.

19. Fartoukh M, Maitre B, Honoré S, Cerf C, Zahar JR, Brun-Buisson C. Diagnosing pneumonia during mechanical ventilation: the clinical pulmonary infection score revisited. Am J Respir Crit Care Med 2003;168(2):173-179.

20. Flanagan PG, Findlay GP, Magee JT, Ionescu A, Barnes RA, Smithies $\mathrm{M}$. The diagnosis of ventilator-associated pneumonia using nonbronchoscopic, non-directed lung lavages. Intensive Care Med 2000; 26(1):20-30.

21. Torres A, Fábregas N, Ewig S, de la Bellacasa JP, Bauer TT, Ramirez J. Sampling methods for ventilator-associated pneumonia: validation using different histologic and microbiological references. Crit Care Med 2000;28(8):2799-2804.

22. Balthazar AB, Von Nowakonski A, De Capitani EM, Bottini PV, Terzi RG, Araújo S. Diagnostic investigation of ventilator-associated pneumonia using bronchoalveolar lavage: comparative study with a postmortem lung biopsy. Braz J Med Biol Res 2001;34(8):9931001.

23. Torres A, el-Ebiary M, Padró L, González J, de la Bellacasa, Ramirez $\mathrm{J}$, et al. Validation of different techniques for the diagnosis of ventilator-associated pneumonia. Comparison with immediate postmortem pulmonary biopsy. Am J Respir Crit Care Med 1994;149(2 Pt 1):324-331.

24. Torres A, El-Ebiary M, Fábregas N, González J, de la Bellacasa JP, Hernández $\mathrm{C}$, et al. Value of intracellular bacteria detection in the diagnosis of ventilator associated pneumonia. Thorax 1996;51(4): 378-384

25. Kirtland SH, Corley DE, Winterbauer RH, Springmeyer SC, Casey KR, Hampson NB, Dreis DF. The diagnosis of ventilator-associated pneumonia: a comparison of histologic, microbiologic, and clinical criteria. Chest 1997;112(2):445-457.

26. Marquette CH, Copin MC, Wallet F, Neviere R, Saulnier F, Mathieu $\mathrm{D}$, et al. Diagnostic tests for pneumonia in ventilated patients: prospective evaluation of diagnostic accuracy using histology as a diagnostic gold standard. Am J Respir Crit Care Med 1995;151(6): 1878-1888.

27. Papazian L, Autillo-Touati A, Thomas P, Bregeon F, Garbe L, Saux $\mathrm{P}$, et al. Diagnosis of ventilator-associated pneumonia: an evaluation of direct examination and presence of intracellular organisms. Anesthesiology 1997;87(2):268-276. 


\section{Recognition of Nosocomial Pneumonia in the Intensive Care Unit}

28. Rouby JJ, Rossignon MD, Nicolas MH, Martin de Lassale E, Cristin $\mathrm{S}$, Grosset J, Viars P. A prospective study of protected bronchoalveolar lavage in the diagnosis of nosocomial pneumonia. Anesthesiology 1989;71(5):679-685.

29. Riaz OJ, Malhotra AK, Aboutanos MB, Duane TM, Goldberg AE, Borchers CT, et al. Bronchoalveolar lavage in the diagnosis of ventilator-associated pneumonia: to quantitate or not, that is the question. Am Surg 2011;77(3):297-303.

30. Christ-Crain M, Müller B. Biomarkers in respiratory tract infections: diagnostic guides to antibiotic prescription, prognostic markers and mediators. Eur Respir J 2007;30(3):556-573.

31. Christ-Crain M, Müller B. Procalcitonin and pneumonia: is it a useful marker? Curr Infect Dis Rep 2007;9(3):233-240.

32. Ip M, Rainer TH, Lee N, Chan C, Chau SS, Leung W, et al. Value of serum procalcitonin, neopterin, and C-reactive protein in differentiating bacterial from viral etiologies in patients presenting with lower respiratory tract infections. Diagn Microbiol Infect Dis 2007; 59(2):131-136.

33. Christ-Crain M, Jaccard-Stolz D, Bingisser R, Gencay MM, Huber PR, Tamm M Müller B. Effect of procalcitonin-guided treatment on antibiotic use and outcome in lower respiratory tract infections: cluster-randomised, single-blinded intervention trial. Lancet 2004; 363(9409):600-607.

34. Christ-Crain M, Stolz D, Bingisser R, Müller C, Miedinger D, Huber $\mathrm{PR}$, et al. Procalcitonin guidance of antibiotic therapy in communityacquired pneumonia: a randomized trial. Am J Respir Crit Care Med 2006;174(1):84-93.

35. Briel M, Schuetz P, Mueller B, Young J, Schild U, Nusbaumer C, et al. Procalcitonin-guided antibiotic use vs a standard approach for acute respiratory tract infections in primary care. Arch Intern Med 2008;168(18):2000-2007. discussion 2007-2008.

36. Ramirez P, Garcia MA, Ferrer M, Aznar J, Valencia M, Sahuquillo $\mathrm{JM}$, et al. Sequential measurements of procalcitonin levels in diagnosing ventilator-associated pneumonia. Eur Respir J 2008;31(2): 356-362.

Dr Kollef's effort was supported by the Barnes-Jewish Hospital Foundation. He has disclosed no other conflicts of interest.

Correspondence: Marin H Kollef MD, Division of Pulmonary and Critical Care Medicine, Washington University School of Medicine, 660 South Euclid Avenue, Campus Box 8052, St Louis MO 63110. E-mail: mkollef@dom.wustl.edu.

DOI: $10.4187 /$ respcare.01409
37. Luyt CE, Combes A, Reynaud C, Hekimian G, Nieszkowska A, Tonnellier M, et al. Usefulness of procalcitonin for the diagnosis of ventilator-associated pneumonia. Intensive Care Med 2008;34(8): $1434-1440$

38. Dallas J, Brown SM, Hock K, Scott MG, Skrupky LP, Boyle WA 3rd, Kollef MH. Diagnostic utility of plasma procalcitonin for nosocomial pneumonia in the ICU setting. Respir Care 2011;56(4):412419.

39. Christ-Crain M, Müller B. Calcitonin peptides-the mediators in sepsis or just another fairy tale? Crit Care Med 2008;36(5):1684-1687.

40. Bouadma L, Luyt CE, Tubach F, Cracco C, Alvarez A, Schwebel C, et al. Use of procalcitonin to reduce patients' exposure to antibiotics in intensive care units (PRORATA trial): a multicentre randomised controlled trial. Lancet 2010;375(9713):463-474.

41. Kollef MH. Will procalcitonin reduce antibiotic use in intensive care? Lancet 2010;375(9713):435-436.

42. Iregui M, Ward S, Sherman G, Fraser VJ, Kollef MH. Clinical importance of delays in the initiation of appropriate antibiotic treatment for ventilator-associated pneumonia. Chest 2002;122(1):262268.

43. Kollef MH, Kollef KE. Antibiotic utilization and outcomes for patients with clinically suspected ventilator-associated pneumonia and negative quantitative BAL culture results. Chest 2005;128(4):27062713.

44. Fagon JY, Chastre J, Wolff M, Gervais C, Parer-Aubas S, Stéphan F, et al. Invasive and noninvasive strategies for management of suspected ventilator-associated pneumonia. A randomized trial. Ann Intern Med 2000;132(8):621-630.

45. Heyland DK, Cook DJ, Marshall J, Heule M, Guslits B, Lang J, Jaeschke R. The clinical utility of invasive diagnostic techniques in the setting of ventilator-associated pneumonia. Canadian Critical Care Trials Group Chest 1999;115(4):1076-1084.

46. Shorr AF, Sherner JH, Jackson WL, Kollef MH. Invasive approaches to the diagnosis of ventilator-associated pneumonia: a meta-analysis. Crit Care Med 2005;33(1):46-53.

47. Canadian Critical Care Trials Group. A randomized trial of diagnostic techniques for ventilator-associated pneumonia. N Engl J Med 2006;355(25):2619-2630.

48. Kollef MH. Diagnosis of ventilator-associated pneumonia. N Engl J Med 2006;355(25):2691-2693. Erratum in: N Engl J Med 2007; 356(12): 1283 .

49. Ibrahim EH, Ward S, Sherman G, Schaiff R, Fraser VJ, Kollef MH. Experience with a clinical guideline for the treatment of ventilatorassociated pneumonia. Crit Care Med 2001;29(6):1109-1115.

50. Micek ST, Ward S, Fraser VJ, Kollef MH. A randomized controlled trial of an antibiotic discontinuation policy for clinically suspected ventilator-associated pneumonia. Chest 2004;125(5):1791-1799. 